\title{
Evidence for a different electronic configuration as a primary effect during compression of orthorhombic perovskites: The case of $\mathrm{Nd}^{3+} \mathrm{O}_{3}(M=\mathrm{Cr}, \mathrm{Ga})$
}

\author{
M. Ardit, ${ }^{1, *}$ M. Dondi, ${ }^{2}$ M. Merli, ${ }^{3}$ and G. Cruciani ${ }^{1}$ \\ ${ }^{1}$ Department of Physics and Earth Sciences, University of Ferrara, I-44122 Ferrara, Italy \\ ${ }^{2}$ Institute of Science and Technology for Ceramics (ISTEC-CNR), I-48018 Faenza, Italy \\ ${ }^{3}$ Department of Earth and Sea Sciences (DiSTeM), University of Palermo, I-90123 Palermo, Italy
}

(Received 18 September 2017; revised manuscript received 26 January 2018; published 14 February 2018)

\begin{abstract}
$(\mathrm{Mg}, \mathrm{Fe}) \mathrm{SiO}_{3}$ perovskite is the most abundant mineral of the Earth's lower mantle, and compounds with the perovskite structure are perhaps the most widely employed ceramics. Hence, they attract both geophysicists and material scientists. Several investigations attempted to predict their structural evolution at high pressure, and recent advancements highlighted that perovskites having ions with the same formal valence at both polyhedral sites (i.e., $3+: 3+$ ) define different compressional patterns when transition metal ions (TMI) are involved. In this study, in situ high-pressure synchrotron XRD measurements coupled with ab initio simulations of the electronic population of $\mathrm{NdCrO}_{3}$ perovskite are compared with the compressional feature of $\mathrm{NdGaO}_{3}$. Almost identical from a steric point of view $\left(\mathrm{Cr}^{3+}\right.$ and $\mathrm{Ga}^{3+}$ have almost the same ionic radius), the different electronic configuration of octahedrally coordinated ions - which leads to a redistribution of electrons at the $3 d$ orbitals for $\mathrm{Cr}^{3+}$ - allows the crystal field stabilization energy (CFSE) to act as a vehicle of octahedral softening in $\mathrm{NdCrO}_{3}$ or it turns octahedra into rigid units when CFSE is null as in $\mathrm{NdGaO}_{3}$. Besides to highlight that different electronic configurations can act as a primary effect during compression of perovskite compounds, our findings have a deep repercussion on the way the compressibility of perovskites have to be modeled.
\end{abstract}

DOI: 10.1103/PhysRevB.97.064106

\section{INTRODUCTION}

Minerals and synthetic compounds with the perovskite structure (general stoichiometry $A B X_{3}$ ) represent a system which equally offers potential developments in countless technological applications (e.g., [1-3]), and given that $(\mathrm{Mg}, \mathrm{Fe}, \mathrm{Al})(\mathrm{Si}, \mathrm{Al}, \mathrm{Fe}) \mathrm{O}_{3}$ bridgmanite is the dominant phase of the Earth's lower mantle, a deeper understanding of the geophysical processes operating at the Earth's mantle depths (e.g., [4-6]).

Like bridgmanite, most perovskite oxides exhibit an orthorhombic symmetry (s.g., Pbnm). Their structure derives from the cubic archetype (s.g., Pm-3m) through chemical variations of the constituent cations (e.g., ionic radius, valence, electronic configuration, etc.) as well as by changes of intensive variables, such as pressure and temperature [7-10].

It follows that understanding the mechanisms governing perovskites at ambient and nonambient conditions is fundamental for both devising functional materials and providing a reliable model of the deep Earth. Indeed, several models and parametrizations have been proposed to predict the evolution of orthorhombic perovskites with pressure from their structural features at ambient conditions [11-13]. The common paradigm on which are founded those models rationalizes the evolution of perovskites with pressure in terms of the relative compressibility of $A \mathrm{O}_{12}$ and $B \mathrm{O}_{6}$ polyhedra [14,15]. Specifically, it has been ascertained that perovskites in which the $A$ cation has a lower formal charge than the $B$ cation (i.e., $2+: 4+$ ), $A \mathrm{O}_{12}$ dodecahedra are more compressible than $\mathrm{BO}_{6}$ octahedra, and the

\footnotetext{
*Corresponding author: rdtmtt@unife.it
}

volume reduction will lead to an increase of the octahedral tilting. Vice versa, perovskites in which $A$ and $B$ cations have the same formal charge (i.e., $3+: 3+$ ), $A \mathrm{O}_{12}$ dodecahedra are less compressible than $\mathrm{BO}_{6}$ octahedra, and the volume reduction is accompanied by a decreasing of the octahedral tilting [13-16].

Although efficient for many perovskite compounds, this model does not hold when transition metal ions (TMI) occur at the $\mathrm{BO}_{6}$ octahedra. Recent advancements reviewed the compressional behavior of perovskites through the so called "normalized cell distortion factor with pressure" $d_{\text {norm }}(P)[17-$ $20]$. The $d_{\text {norm }}(P)$ takes origin from the "cell distortion factor" $d$ [21], formulated to evaluate the departure of an orthorhombic perovskite from the cubic archetype (where $d=0$ ) at ambient conditions. Since in the Pbnm space group $a \approx b \approx \sqrt{ } 2 a_{\mathrm{p}}$, and $c \approx 2 a_{\mathrm{p}}$, with $a_{\mathrm{p}}$ a pseudocubic subcell parameter defined as $(a / \sqrt{ } 2+b / \sqrt{ } 2+c / 2) / 3$, the cell distortion factor is defined as $d=\left[\left(a / \sqrt{ } 2-a_{\mathrm{p}}\right)^{2}+\left(b / \sqrt{ } 2-a_{\mathrm{p}}\right)^{2}+\left(c / 2-a_{\mathrm{p}}\right)^{2}\right] / 3 a_{\mathrm{p}}^{2} \times$ $10^{4}$. In order to evaluate the lattice distortion of an orthorhombic perovskite at high pressure regimes, the $d$ factor has been extended by means of the normalized cell distortion factor with pressure as $d_{\text {norm }}(P)=1 / d_{0}(\partial d / \partial P)_{T}$ (where $d_{0}$ is the cell distortion factor $d$ at ambient condition) $[17,18]$. Specifically, the latter parameter provides the rate of change of the lattice distortion of an orthorhombic perovskite with pressure, including both possible lattice anisotropies and variations of the octahedral tilts. By means of the $d_{\text {norm }}(P)$ it has been demonstrated that both perovskites 2:4 (e.g., $\mathrm{CaGeO}_{3}$ [17]) and 3:3 (e.g., $\mathrm{YTiO}_{3}$ and $\mathrm{YAl}_{0.25} \mathrm{Cr}_{0.75} \mathrm{O}_{3}$ [17-20]) can violate what was forecasted by the previous model. In particular, it has been highlighted that perovskites 3:3 can define different compressional patterns whether $T M I$ are hosted at the octahedral 
site $[19,20]$. The latter evidence assumes a high impact both in materials sciences (many of the extraordinary properties of new functional materials derive from the presence of TMI in their chemistry, e.g., [22]) and in Earth sciences, considering that the bridgmanite mineral is likely incorporating $T M I$, such as $\mathrm{Fe}, \mathrm{Cr}$, and Ti (e.g., [6,23,24]).

This picture becomes even more complex, and the predictive accuracy of these models decreases, when perovskites with similar features at ambient conditions (e.g., characterized by cations with the same formal valence, very similar ionic radii of the constituent cations, same degree of octahedral tilting, etc.) behave in a different way with pressure.

This is the case of gallate and chromate orthorhombic perovskites. Isostructural at ambient conditions, the $\mathrm{LaGaO}_{3}-\mathrm{LaCrO}_{3}$ and $\mathrm{NdGaO}_{3}-\mathrm{NdCrO}_{3}$ couples undergo an orthorhombic (space group Pbnm) to rhombohedral (s.g., $R-3 c$ ) phase transition, $\mathrm{O}-\mathrm{R}$, at high-temperature as well as at high-pressure conditions [25-32]. From a steric point of view, octahedrally coordinated $\mathrm{Cr}^{3+}$ and $\mathrm{Ga}^{3+}$ have approximately the same ionic radius ( 0.615 and $0.62 \AA$, respectively) and very similar dipole polarizability (1.45 and $1.50 \AA^{3}$, respectively). Thus, through the compressional models of orthorhombic perovskites $[13,16,19]$, it would be expected that $\mathrm{La}$ and $\mathrm{Nd}$ couples of perovskites present similar compressional paths, namely comparable transition pressures from the orthorhombic to the rhombohedral phase. On the other hand, it is rather peculiar that both $\mathrm{La}$ and $\mathrm{Nd}$ perovskites are characterized by temperatures and pressures of transition which differ substantially from each other [25-32].

The dualism between $\mathrm{Cr}^{3+}$ and $\mathrm{Ga}^{3+}$ hosted at the octahedral site of orthorhombic perovskites is a perfect case study to appraise how a specific electronic configuration acts during the compression of these compounds, with particular attention to the crystal field stabilization energy (CFSE). The underlying question is whether the different electronic configurations of $\mathrm{Cr}^{3+}$ and $\mathrm{Ga}^{3+}$ play a primary role during the compression of chromate and gallate orthorhombic perovskites by considering that $\mathrm{Ga}^{3+}$ has full $3 d$ orbitals, while $\mathrm{Cr}^{3+}$ is a TMI with partially filled $3 d$ orbitals stabilized at octahedral sites by the crystal field effect [33].

In this contribution, the structural modifications of $\mathrm{NdCrO}_{3}$ perovskite at high-pressure conditions have been investigated by means of synchrotron x-ray diffraction coupled with an $a b$ initio simulation at the HF/DFT level of the experimental structures, and compared to those of isostructural $\mathrm{NdGaO}_{3}$ and $\mathrm{La}(\mathrm{Ga}, \mathrm{Cr}) \mathrm{O}_{3}$ perovskite compounds.

\section{EXPERIMENTAL PROCEDURE}

\section{A. Sample preparation}

A polycrystalline sample of $\mathrm{NdCrO}_{3}$ perovskite was synthesized via solid-state reaction by using reagent-grade $\mathrm{Nd}_{2} \mathrm{O}_{3}$ and $\mathrm{Cr}_{2} \mathrm{O}_{3}$ with $>99 \%$ of purity. These precursors were supplied by Merck. The raw materials were mixed and homogenized by ball milling in acetone, then oven dried at $100{ }^{\circ} \mathrm{C}$. Dry powders were iteratively calcined into an unsealed alumina crucible at $1300{ }^{\circ} \mathrm{C}$ for several hours, until the preliminary $\mathrm{X}$-ray diffraction analysis revealed a monophasic compound.
Each cycle of calcination was followed by natural cooling to room temperature.

\section{B. Synchrotron $x$-ray powder diffraction}

In situ high-pressure x-ray diffraction experiments were conducted at the European Synchrotron Radiation Facility (beamline ID27). Hydrostatic pressure was generated up to $21 \mathrm{GPa}$ on the $\mathrm{NdCrO}_{3}$ perovskite sample using a cylinderpiston type diamond anvil cell with culet faces of $300 \mu \mathrm{m}$ diameter. Powders were loaded into a preindented gasket hole (i.e., a rhenium foil of $50 \mu \mathrm{m}$ thickness) with $150 \mu \mathrm{m}$ diameter, and $\mathrm{He}$ as the pressure-transmitting medium [34]. A small single-crystalline ruby sphere was loaded into the cell in order to measure the pressure by means of the fluorescence method [35]. The wavelength of the monochromatic incident $\mathrm{x}$-ray beam was $\lambda=0.3738 \AA$, which corresponds to the iodine $K$ edge. Debye-Sherrer rings were collected with a MAR 165 circular CCD detector with an active imaging surface of $165 \mathrm{~mm}$ diameter and pixel size at CCD of $15 \times 15 \mu \mathrm{m}$. The accessible angular range was within the limit imposed by the aperture of the diamond anvil cell (i.e., approximately $20^{\circ}$ in $2 \theta$ ).

The collected data were reduced and integrated radially over the full rings by the DIOPTAS program [36], using beam center, detector tilt, and sample to detector distance determined from a powder diffraction pattern of $\mathrm{CeO}_{2}$ as standard, in order to obtain the conventional intensity vs $2 \theta$ angle patterns. Furthermore, all the diffraction peaks of diamond and solid $\mathrm{He}$ (above $12 \mathrm{GPa}$ ) were masked. In order to check the goodness of the reduced data, a refinement of the unit-cell parameters was performed sequentially by SEQGSAS and SEQPLOT programs, within the EXPGUI-GSAS suite [37,38], and reported in Table $\mathrm{I}$.

\section{Rietveld refinements}

The EXPGUI v.1251 interface for the GSAS program was used for Rietveld refinements [37,38]. The structure refinement of the $\mathrm{NdCrO}_{3}$ orthorhombic perovskite was carried out in the Pbnm space group, starting from the structural model (i.e., cell parameters, fractional atomic coordinates and isotropic atomic displacement parameters, ADPs) of $\mathrm{NdGaO}_{3}$ [30], with $\mathrm{Cr}$ replacing $\mathrm{Ga}$. The diffraction peak profile was modeled by a pseudo-Voigt function, which included three Gaussian (i.e., $\mathrm{GU}, \mathrm{GV}$, and GW, respectively) and two Lorentzian (i.e., LX and LY, respectively) broadening coefficients, plus an asymmetry contribution. Besides that, 24 shifted Chebyshev polynomial coefficients were employed to reproduce the background. The variation of the atomic coordinates with pressure have been refined up to $12.65 \mathrm{GPa}$, as difficulties in reliable extraction of the diffracted intensities was encountered for collected data at the highest pressures investigated. The ADPs for data collected between 9.56 and 12.65 GPa have been constrained to the average of those collected at lower pressures. Final atomic coordinates and isotropic ADPs of $\mathrm{NdCrO}_{3}$ perovskite up to 12.65 are provided in Table II. Furthermore, a selection of polyhedral bond distances, polyhedral volumes, and interoctahedral bond angles from structural refinement of $\mathrm{NdCrO}_{3}$ perovskite up to $8.3 \mathrm{GPa}$ are listed in Table III. Two representative Rietveld plots are given in Fig. 1. 
TABLE I. Unit-cell parameters of $\mathrm{NdCrO}_{3}$ perovskite up to $20.60 \mathrm{GPa}$.

\begin{tabular}{|c|c|c|c|c|}
\hline \multicolumn{5}{|c|}{$\mathrm{NdCrO}_{3}$ (space group $\mathrm{Pbnm} ; Z=4$ ) } \\
\hline$P(\mathrm{GPa})$ & $a(\AA)$ & $b(\AA)$ & $c(\AA)$ & $V\left(\AA^{3}\right)$ \\
\hline $0.03(5)$ & $5.42040(19)$ & $5.48513(21)$ & $7.69268(32)$ & $228.716(15)$ \\
\hline $0.63(7)$ & $5.41576(16)$ & $5.47723(18)$ & $7.68638(26)$ & $228.004(12)$ \\
\hline $1.69(8)$ & $5.40827(9)$ & $5.46439(10)$ & $7.67271(15)$ & $226.751(7)$ \\
\hline $2.79(12)$ & $5.40163(17)$ & $5.45195(18)$ & $7.66063(27)$ & $225.601(12)$ \\
\hline $3.87(9)$ & $5.39410(15)$ & $5.43907(17)$ & $7.64692(25)$ & $224.352(10)$ \\
\hline $4.81(8)$ & $5.38875(13)$ & $5.42912(14)$ & $7.63695(22)$ & $223.428(9)$ \\
\hline $6.06(7)$ & $5.38046(17)$ & $5.41476(19)$ & $7.62086(29)$ & $222.025(10)$ \\
\hline $7.59(6)$ & $5.37118(16)$ & $5.39801(18)$ & $7.60220(28)$ & $220.416(9)$ \\
\hline $8.30(7)$ & $5.36738(16)$ & $5.39088(17)$ & $7.59587(27)$ & $219.786(8)$ \\
\hline $9.56(10)$ & $5.35880(20)$ & $5.37779(21)$ & $7.58286(34)$ & $218.527(8)$ \\
\hline $11.09(11)$ & $5.34987(28)$ & $5.36265(27)$ & $7.56932(47)$ & $217.160(8)$ \\
\hline $12.20(11)$ & $5.34356(37)$ & $5.35180(30)$ & $7.55770(59)$ & 216.133(8) \\
\hline $12.65(11)$ & $5.34185(32)$ & $5.34778(25)$ & $7.55283(48)$ & $215.762(7)$ \\
\hline $13.95(10)$ & $5.33425(53)$ & $5.33423(30)$ & $7.53913(72)$ & $214.519(7)$ \\
\hline $15.18(12)$ & $5.32839(68)$ & $5.32237(34)$ & $7.52693(93)$ & 213.461(9) \\
\hline $16.67(11)$ & $5.32134(39)$ & $5.30846(23)$ & $7.51229(57)$ & $212.208(7)$ \\
\hline 18.11(13) & $5.31439(32)$ & $5.29607(26)$ & 7.49904(49) & 211.064(9) \\
\hline $19.42(9)$ & $5.30767(27)$ & $5.28437(26)$ & $7.48596(43)$ & $209.964(11)$ \\
\hline $20.60(10)$ & $5.30288(23)$ & $5.27542(24)$ & $7.47566(37)$ & 209.131(11) \\
\hline
\end{tabular}

\section{Computational details}

Static energy calculations were carried out by the HF/DFTCRYSTAL14 program [39], which implements "ab initio linear-combination-of-atomic-orbitals" in the case of periodic systems. A Hamiltonian based on the WC1LYP functional was used [40]. The following values were used in order to evaluate the integral tolerances in the HF procedure: $10^{-6}$ for Coulomb overlap, $10^{-6}$ for Coulomb penetration, $10^{-6}$ for exchange overlap, $10^{-6}$ for exchange pseudo-overlap in direct space, $10^{-12}$ for exchange pseudo-overlap in reciprocal space, and

TABLE II. Atomic fractional coordinates $\left(x, y\right.$, and $z$ ), and isotropic $\mathrm{ADPs}\left(U_{\text {iso }}\right)$ of $\mathrm{NdCrO}_{3}$ perovskite up to $12.65 \mathrm{GPa}$ (see the experimental procedure section for further details). Fixed coordinates, $A$ site: $z=1 / 4 ; B$ site: $x=1 / 2$, and $y=z=0 ; \mathrm{O} 1: z=1 / 4$.

\begin{tabular}{|c|c|c|c|c|c|c|c|c|}
\hline \multicolumn{9}{|c|}{$\mathrm{NdCrO}_{3}$ (space group $\mathrm{Pbnm} ; Z=4$ ) } \\
\hline$P(\mathrm{GPa})$ & & $0.03(5)$ & $0.63(7)$ & $1.69(8)$ & $2.79(12)$ & $3.87(9)$ & $4.81(8)$ & $6.06(7)$ \\
\hline \multirow[t]{3}{*}{$\mathrm{Nd}$} & $x$ & $0.9976(16)$ & $0.9946(9)$ & $0.9930(4)$ & $0.9965(13)$ & $0.9973(14)$ & $0.9963(10)$ & $0.9978(18)$ \\
\hline & $y$ & $0.04324(27)$ & $0.04156(22)$ & $0.04129(13)$ & $0.04068(23)$ & $0.03961(21)$ & $0.03929(17)$ & $0.03932(22)$ \\
\hline & $U_{\text {iso }}$ & $0.41(5)$ & $0.45(4)$ & $0.49(2)$ & $0.43(4)$ & $0.43(4)$ & $0.45(3)$ & $0.46(4)$ \\
\hline $\mathrm{Cr}$ & $U_{\text {iso }}$ & $0.34(10)$ & $0.36(8)$ & $0.34(4)$ & $0.30(8)$ & $0.35(7)$ & $0.36(6)$ & $0.31(7)$ \\
\hline \multirow[t]{3}{*}{ O1 } & $x$ & $0.0938(11)$ & $0.0962(8)$ & $0.0954(5)$ & $0.0976(7)$ & $0.0943(9)$ & $0.0958(6)$ & $0.0985(7)$ \\
\hline & $y$ & $0.4849(30)$ & $0.4836(26)$ & $0.4778(15)$ & $0.4888(28)$ & $0.4753(25)$ & $0.4804(21)$ & $0.4884(27)$ \\
\hline & $U_{\text {iso }}$ & $0.46(7)$ & $0.64(6)$ & $0.52(4)$ & $0.35(7)$ & $0.51(6)$ & $0.56(5)$ & $0.16(7)$ \\
\hline \multirow[t]{4}{*}{$\mathrm{O} 2$} & $x$ & $0.7265(25)$ & $0.7011(15)$ & $0.7065(11)$ & $0.7012(15)$ & $0.7062(17)$ & $0.7105(17)$ & $0.7166(26)$ \\
\hline & $y$ & $0.2837(25)$ & $0.3086(15)$ & $0.3030(11)$ & $0.3084(15)$ & $0.3034(17)$ & $0.2992(17)$ & $0.2931(25)$ \\
\hline & $Z$ & $0.0611(13)$ & $0.0401(19)$ & $0.0442(11)$ & $0.0353(22)$ & $0.0389(21)$ & $0.0418(18)$ & $0.0465(21)$ \\
\hline & $U_{\text {iso }}$ & $0.83(5)$ & $0.36(4)$ & $0.40(3)$ & $0.22(4)$ & $0.33(4)$ & $0.26(3)$ & $0.58(4)$ \\
\hline$\overline{P(\mathrm{GPa})}$ & & $7.59(6)$ & $8.30(7)$ & $9.56(10)$ & $11.09(11)$ & $12.20(11)$ & $12.65(11)$ & \\
\hline \multirow[t]{3}{*}{$\mathrm{Nd}$} & $x$ & $0.9984(19)$ & $0.9973(13)$ & $0.9955(10)$ & $0.9965(13)$ & $0.9998(34)$ & $0.9993(26)$ & \\
\hline & $y$ & $0.03758(20)$ & $0.03794(17)$ & $0.03712(19)$ & $0.03804(21)$ & $0.03674(24)$ & $0.03672(19)$ & \\
\hline & $U_{\text {iso }}$ & $0.46(3)$ & $0.48(3)$ & 0.50 & 0.50 & 0.50 & 0.50 & \\
\hline $\mathrm{Cr}$ & $U_{\text {iso }}$ & $0.38(6)$ & $0.36(5)$ & 0.40 & 0.40 & 0.40 & 0.40 & \\
\hline \multirow[t]{3}{*}{ O1 } & $x$ & $0.0972(6)$ & $0.0963(5)$ & $0.0960(5)$ & $0.0964(5)$ & $0.0906(12)$ & $0.0930(8)$ & \\
\hline & $y$ & $0.4885(24)$ & $0.4869(21)$ & $0.4885(24)$ & $0.5073(28)$ & $0.4718(32)$ & $0.4811(25)$ & \\
\hline & $U_{\text {iso }}$ & $0.60(7)$ & $0.40(6)$ & 0.60 & 0.60 & 0.60 & 0.60 & \\
\hline \multirow[t]{4}{*}{$\mathrm{O} 2$} & $x$ & $0.7162(23)$ & $0.7161(21)$ & $0.7129(20)$ & $0.7095(14)$ & $0.7186(30)$ & $0.7195(24)$ & \\
\hline & $y$ & $0.2934(22)$ & $0.2937(21)$ & $0.2967(19)$ & $0.3001(14)$ & $0.2910(30)$ & $0.2900(24)$ & \\
\hline & $Z$ & $0.0415(21)$ & $0.0396(20)$ & $0.0314(26)$ & $0.0223(28)$ & $0.0305(35)$ & $0.0295(28)$ & \\
\hline & $U_{\text {iso }}$ & $0.53(4)$ & $0.68(3)$ & 0.60 & 0.60 & 0.60 & 0.60 & \\
\hline
\end{tabular}


TABLE III. Selection of polyhedral bond distances (i.e., $\mathrm{Nd}-\mathrm{O}$ and $\mathrm{Cr}-\mathrm{O}$ in $\AA$ ), polyhedral volumes [i.e., $V\left(\mathrm{NdO}_{12}\right)$ and $V\left(\mathrm{CrO}_{6}\right)$ in $\AA^{3}$ ], and interoctahedral bond angles (i.e., $\mathrm{Cr}-\mathrm{O}-\mathrm{O}$ in deg), from structural refinement of $\mathrm{NdCrO}_{3}$ perovskite up to $8.30 \mathrm{GPa}$. Standard deviations are reported in parentheses.

\begin{tabular}{|c|c|c|c|c|c|c|c|c|c|}
\hline \multicolumn{10}{|c|}{$\mathrm{NdCrO}_{3}$ (space group $\mathrm{Pbnm} ; Z=4$ ) } \\
\hline$P(\mathrm{GPa})$ & $\mathrm{Nd}-\mathrm{O} 1$ & $\mathrm{Nd}-\mathrm{O} 1$ & $\mathrm{Nd}-\mathrm{O} 1$ & $\mathrm{Nd}-\mathrm{O} 1$ & $\mathrm{Nd}-\mathrm{O} 2[\mathrm{x} 2]$ & $\mathrm{Nd}-\mathrm{O} 2[\mathrm{x} 2]$ & $\mathrm{Nd}-\mathrm{O} 2[\mathrm{x} 2]$ & $\mathrm{Nd}-\mathrm{O} 2[\mathrm{x} 2]$ & ${ }^{\mathrm{XII}}\langle\mathrm{Nd}-\mathrm{O}\rangle$ \\
\hline $0.03(5)$ & $3.106(11)$ & $2.478(9)$ & $3.221(11)$ & $2.238(8)$ & $2.452(5)$ & $2.369(5)$ & $2.858(9)$ & $3.344(8)$ & $2.757(8)$ \\
\hline $0.63(7)$ & $3.105(10)$ & $2.483(8)$ & $3.215(9)$ & $2.239(6)$ & $2.696(5)$ & $2.314(5)$ & $2.626(7)$ & $3.371(7)$ & $2.755(7)$ \\
\hline $1.69(8)$ & $3.128(6)$ & $2.449(4)$ & $3.201(5)$ & $2.253(4)$ & $2.634(3)$ & $2.314(3)$ & $2.675(4)$ & $3.358(4)$ & $2.749(4)$ \\
\hline $2.79(12)$ & $3.058(10)$ & $2.504(8)$ & $3.221(10)$ & $2.211(7)$ & $2.717(5)$ & $2.334(5)$ & $2.584(7)$ & $3.326(7)$ & $2.743(7)$ \\
\hline $3.87(9)$ & $3.114(9)$ & $2.427(7)$ & $3.210(9)$ & $2.231(6)$ & $2.670(5)$ & $2.337(5)$ & $2.623(6)$ & $3.305(6)$ & $2.738(6)$ \\
\hline $4.81(8)$ & $3.081(8)$ & $2.454(6)$ & $3.207(8)$ & $2.221(5)$ & $2.625(4)$ & $2.339(4)$ & $2.659(6)$ & $3.292(5)$ & $2.733(6)$ \\
\hline $6.06(7)$ & $3.032(10)$ & $2.491(8)$ & $3.220(10)$ & $2.189(7)$ & $2.566(5)$ & $2.348(5)$ & $2.705(8)$ & $3.272(7)$ & $2.726(7)$ \\
\hline $7.59(6)$ & $3.011(10)$ & $2.491(8)$ & $3.210(10)$ & $2.188(7)$ & $2.592(5)$ & $2.362(5)$ & $2.667(7)$ & $3.233(7)$ & $2.717(7)$ \\
\hline $8.30(7)$ & $3.018(9)$ & $2.478(8)$ & $3.198(10)$ & $2.198(6)$ & $2.595(5)$ & $2.366(5)$ & $2.654(7)$ & $3.225(7)$ & $2.714(7)$ \\
\hline$P(\mathrm{GPa})$ & $\mathrm{Cr}-\mathrm{O} 1$ [x2] & $\mathrm{Cr}-\mathrm{O} 2$ [x2] & $\mathrm{Cr}-\mathrm{O} 2^{\prime}[\mathrm{x} 2]$ & $\langle\mathrm{Cr}-\mathrm{O}\rangle$ & $V\left(\mathrm{NdO}_{12}\right)$ & $V\left(\mathrm{CrO}_{6}\right)$ & $\mathrm{Cr}-\mathrm{O} 1-\mathrm{Cr}$ & $\mathrm{Cr}-\mathrm{O} 2-\mathrm{Cr}$ & $\langle\mathrm{Cr}-\mathrm{O}-\mathrm{Cr}\rangle$ \\
\hline$\overline{0.03(5)}$ & $1.991(5)$ & $2.037(5)$ & $1.956(5)$ & $1.995(5)$ & $46.642(35)$ & $10.537(32)$ & $150.03(32)$ & $149.84(21)$ & $149.94(27)$ \\
\hline $0.63(7)$ & $1.993(3)$ & $2.034(3)$ & $1.953(3)$ & $1.993(3)$ & $46.460(30)$ & $10.541(27)$ & $149.22(21)$ & 149.99(15) & 149.61(18) \\
\hline $1.69(8)$ & $1.990(2)$ & $2.026(2)$ & $1.948(2)$ & $1.988(2)$ & $46.229(18)$ & $10.459(16)$ & $149.12(12)$ & 150.69(09) & $149.91(11)$ \\
\hline $2.79(12)$ & $1.987(3)$ & $2.020(3)$ & $1.941(3)$ & $1.983(3)$ & $46.042(27)$ & $10.358(24)$ & $149.04(20)$ & $151.21(15)$ & $150.13(18)$ \\
\hline $3.87(9)$ & $1.983(2)$ & $2.012(2)$ & $1.935(2)$ & $1.977(2)$ & $45.816(24)$ & $10.272(22)$ & 149.23(17) & $152.03(13)$ & $150.63(15)$ \\
\hline $4.81(8)$ & $1.981(2)$ & $2.007(2)$ & $1.930(2)$ & $1.972(2)$ & $45.642(21)$ & $10.215(19)$ & $149.13(15)$ & 152.61(12) & $150.87(14)$ \\
\hline $6.06(7)$ & $1.979(2)$ & $2.001(2)$ & $1.925(2)$ & $1.968(2)$ & $45.353(24)$ & $10.153(21)$ & $148.70(17)$ & $152.93(14)$ & $150.82(16)$ \\
\hline $7.59(6)$ & $1.972(2)$ & $1.989(2)$ & $1.915(2)$ & $1.959(2)$ & $45.102(21)$ & $10.002(19)$ & 149.07(16) & $154.46(13)$ & $151.77(15)$ \\
\hline $8.30(7)$ & $1.969(2)$ & $1.986(2)$ & $1.910(2)$ & $1.955(2)$ & $45.003(36)$ & $9.944(35)$ & $149.29(14)$ & $155.00(12)$ & $152.15(13)$ \\
\hline$P(\mathrm{GPa})$ & $\mathrm{O} 1-\mathrm{Cr}-\mathrm{O} 1$ & $\begin{array}{c}\mathrm{O} 1-\mathrm{Cr}-\mathrm{O} 2 \\
{[\mathrm{x} 2]}\end{array}$ & $\begin{array}{c}\mathrm{O} 1-\mathrm{Cr}-\mathrm{O} 2 \\
{[\mathrm{x} 2]}\end{array}$ & $\begin{array}{c}\mathrm{O} 1-\mathrm{Cr}-\mathrm{O} 2 \\
{[\mathrm{x} 2]} \\
\end{array}$ & $\begin{array}{c}\mathrm{O} 1-\mathrm{Cr}-\mathrm{O} 2 \\
{[\mathrm{x} 2]}\end{array}$ & $\begin{array}{c}\mathrm{O} 2-\mathrm{Cr}-\mathrm{O} 2 \\
{[\mathrm{x} 2]}\end{array}$ & $\begin{array}{c}\mathrm{O} 2-\mathrm{Cr}-\mathrm{O} 2 \\
{[\mathrm{x} 2]}\end{array}$ & $\begin{array}{c}\mathrm{O} 1-\mathrm{Cr}-\mathrm{O} 2 \\
{[\mathrm{x} 2]}\end{array}$ & \\
\hline $0.03(5)$ & 180.00 & $87.9(4)$ & $86.3(5)$ & $92.1(4)$ & $93.7(5)$ & $87.20(11)$ & 180.00 & $92.80(11)$ & \\
\hline $0.63(7)$ & 180.00 & $91.8(4)$ & $92.3(6)$ & $88.2(4)$ & $87.7(6)$ & $88.76(12)$ & 180.00 & $91.24(12)$ & \\
\hline $1.69(8)$ & 180.00 & $91.8(3)$ & $90.6(4)$ & $88.2(3)$ & $89.4(4)$ & $88.47(8)$ & 180.00 & $91.53(8)$ & \\
\hline $2.79(12)$ & 180.00 & $92.2(5)$ & $94.0(7)$ & $87.8(5)$ & $86.0(7)$ & $88.96(12)$ & 180.00 & $91.04(12)$ & \\
\hline $3.87(9)$ & 180.00 & $93.1(4)$ & $91.4(7)$ & $86.9(4)$ & $88.6(7)$ & $88.73(13)$ & 180.00 & $91.27(13)$ & \\
\hline $4.81(8)$ & 180.00 & $92.1(4)$ & $91.2(6)$ & $87.9(4)$ & $88.8(6)$ & $88.51(12)$ & 180.00 & $91.49(12)$ & \\
\hline $6.06(7)$ & 180.00 & $90.6(5)$ & $90.9(7)$ & $89.4(5)$ & $89.1(7)$ & $88.14(15)$ & 180.00 & $91.86(15)$ & \\
\hline $7.59(6)$ & 180.00 & $91.5(4)$ & $91.9(6)$ & $88.5(4)$ & $88.1(6)$ & $88.44(13)$ & 180.00 & $91.56(13)$ & \\
\hline $8.30(7)$ & 180.00 & $92.0(4)$ & $92.1(6)$ & $88.0(4)$ & $87.9(6)$ & $88.53(12)$ & 180.00 & $91.47(12)$ & \\
\hline
\end{tabular}

$10^{-9}$ a.u. threshold for SCF-cycles convergence. The 8-411d1 [41], 86-411d41G [42], 86-4111d41G [43] basis sets were employed for $\mathrm{O}, \mathrm{Cr}$, and $\mathrm{Ga}$ atoms, respectively. The $\mathrm{Nd}$ basis set was created by means of the "atomicbilly" utility [44]. The exponents of the outer GTFs were reoptimized for all basis sets. The diagonalization of the Fock matrix was performed
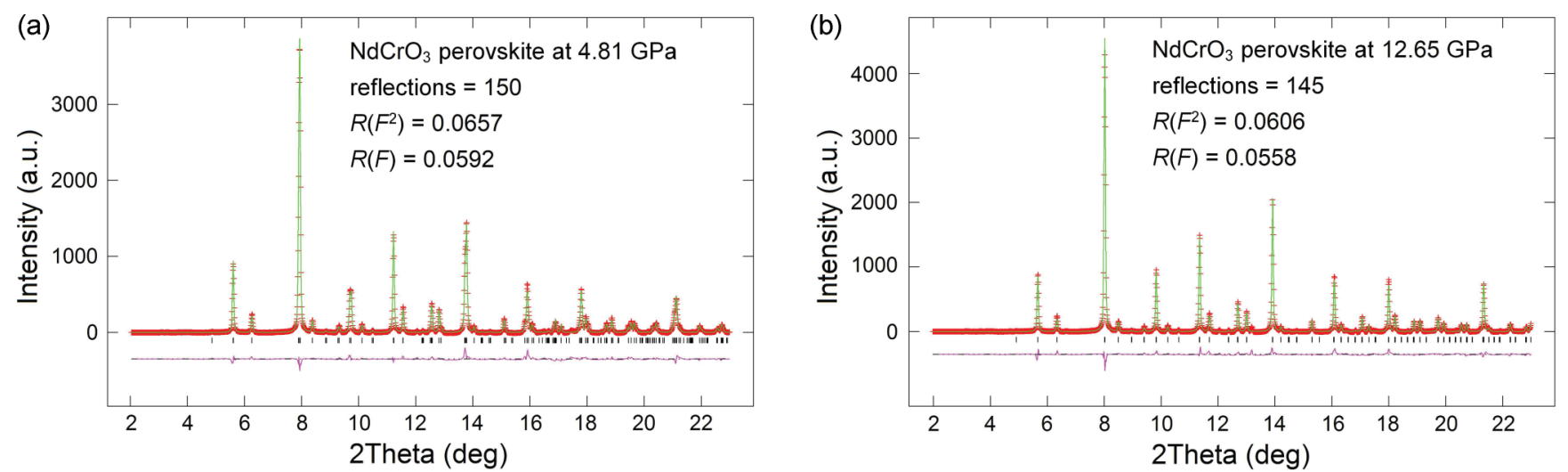

FIG. 1. Plot of the Rietveld refinements for $\mathrm{NdCrO}_{3}$ perovskite at 4.81 and $12.65 \mathrm{GPa}$ at room temperature $(\lambda=0.3738 \AA)$. The experimental data are indicated by crosses (red), the calculated pattern is the continuous line (light green), whereas the lower curve (purple) is the weighted difference between the observed and calculated patterns. Vertical ticks mark the position of reflections for perovskite in the Pbnm space group. 
(a)

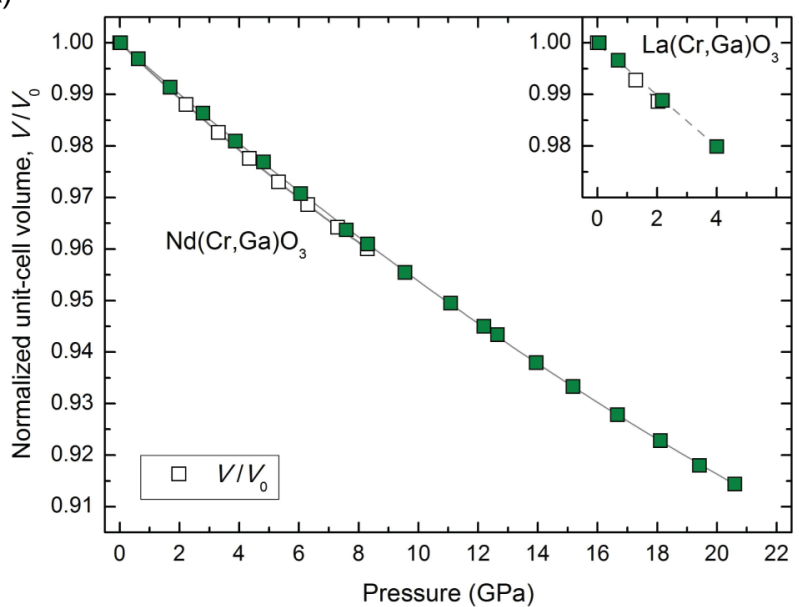

(b)

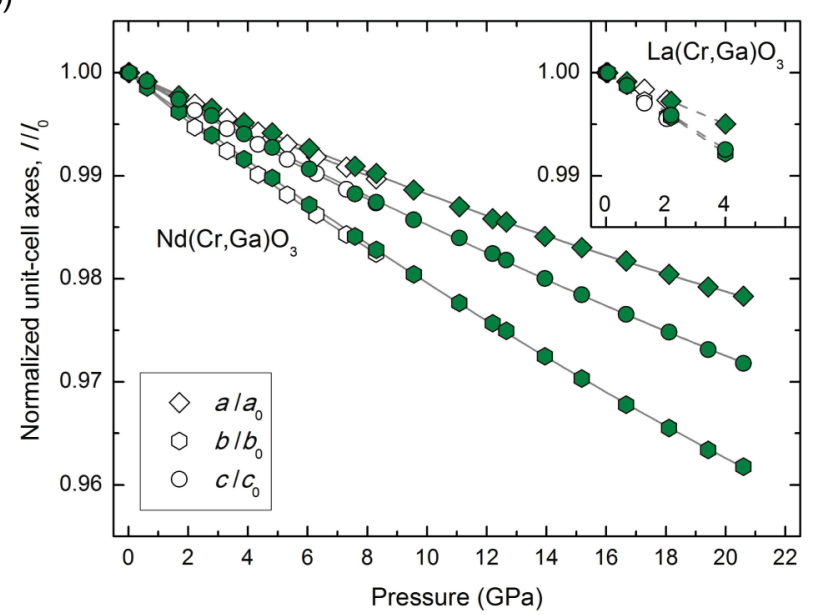

FIG. 2. Pressure dependence of normalized unit-cell volume (a) and unit-cell parameters (b) for $\mathrm{NdGaO}_{3}-\mathrm{NdCrO}_{3}$ and $\mathrm{LaGaO}_{3}-\mathrm{LaCrO}_{3}$ (within the insets) couples of perovskites. Data for $\mathrm{LaCrO}_{3}$ and $\mathrm{LaGaO}_{3}$ are plotted before the O-R phase transition occurs. Filled and empty symbols refer to $\mathrm{Cr}$ and $\mathrm{Ga}$ compounds, respectively. Symbol sizes exceed the estimated uncertainties in measurements. Lines are the equation of state $(\mathrm{EoS})$ fit to the data (see Table I).

at 64 points in the reciprocal space (Monkhorst net) [45]. Each structure was modeled from the experimental unit-cell volumes fixed at a given pressure, but allowing relaxation of the atomic positions to reduce the noise intrinsically introduced by the uncertainty on the atom coordinates refined by Rietveld procedure. At the end of each run a Mulliken population analysis has been performed to estimate orbital charges derived from calculations.

\section{RESULTS AND DISCUSSION}

\section{A. EoS and unit-cell parameters}

Within the investigated pressure range, the unit-cell volume and unit-cell parameters of $\mathrm{NdCrO}_{3}$ perovskite vary continuously and smoothly with pressure, and no evidence of phase transition is observed (Table I and Fig. 2).

In addition, Fig. 2 shows that $\mathrm{Nd}$ and $\mathrm{La}$ couples of perovskites are characterized by compressional paths that are overlapped (within uncertainties), and by an almost identical axial anisotropy. This behavior can be observed within the stability field of $\mathrm{Pbnm}$ phases (since both $\mathrm{Ga}$ and $\mathrm{Cr}$ lanthanum compounds are known to suffer a first-order phase transition at about 2.2 and 5.5 GPa, respectively [26-31]). In detail, the compressibility of La compounds along [100] (i.e., the $a$ axis) is approximately 1.6 times stiffer than that along [010] and [001]. It means that $b$ and $c$ axes have very similar compressibilities, and the axial compressibility scheme is $K_{a 0} / K_{b 0}$ : $K_{b 0} / K_{b 0}: K_{c 0} / K_{b 0}=1.6: 1.0: 1.0$. In contrast, $\mathrm{Nd}$ compounds show an increased lattice parameters anisotropy, with the [010] direction being softened and the [001] direction turning stiffer. In fact, the axial compressibility scheme is $K_{a 0} / K_{b 0}: K_{b 0} / K_{b 0}: K_{c 0} / K_{b 0}=1.7: 1.0: 1.4$ for $\mathrm{Nd}$ samples.

Volumetric and axial moduli obtained by a data fitting to a Birch-Murnaghan third-order equation of state (BM3$\mathrm{EoS}$ ) for $\mathrm{La}$ and $\mathrm{Nd}$ couples of perovskites are provided in

TABLE IV. Comparison of volumetric and axial moduli obtained by data fitting to a Birch-Murnaghan third-order equation of state (BM3-EoS), with the axial moduli obtained by fitting the data to the cubes of each cell axis, and bulk modulus of cubic and octahedral polyhedron of the $\mathrm{Nd}$ perovskite oxides obtained by data fitting to a Birch-Murnaghan second-order equation of state (BM2-EoS). ${ }^{\mathrm{a}}$

\begin{tabular}{|c|c|c|c|c|c|c|c|c|c|c|c|}
\hline & $\begin{array}{c}K_{T 0}(\mathrm{GPa}) \\
K_{0}^{\prime}\end{array}$ & $\begin{array}{c}K_{a 0}(\mathrm{GPa}) \\
K_{a 0}^{\prime}\end{array}$ & $\begin{array}{c}K_{b 0}(\mathrm{GPa}) \\
K_{b 0}^{\prime}\end{array}$ & $\begin{array}{c}K_{c 0}(\mathrm{GPa}) \\
K_{c 0}^{\prime}\end{array}$ & $\begin{array}{c}P_{\max } \\
(\mathrm{GPa})\end{array}$ & EoS & $\begin{array}{c}K_{(A O 12) 0} \\
(\mathrm{GPa})\end{array}$ & $\begin{array}{c}K_{(\text {BO6)0 }} \\
(\mathrm{GPa})\end{array}$ & $\begin{array}{c}P_{\max } \\
(\mathrm{GPa})\end{array}$ & EoS & Ref. \\
\hline \multirow[t]{2}{*}{$\mathrm{LaGaO}_{3}$} & $172(1)$ & $238(3)$ & $153(3)$ & $148(1)$ & $2.0(1)$ & BM3 & - & - & - & & {$[30]$} \\
\hline & 6.4 (fixed) & 9 (fixed) & 6.3 (fixed) & 5.4 (fixed) & & & & & & & \\
\hline \multirow[t]{2}{*}{$\mathrm{LaCrO}_{3}$} & $183(4)$ & $242(5)$ & $160(5)$ & $166(6)$ & $4.0(1)$ & BM3 & - & - & - & & fitting of data from [31] \\
\hline & $5.4(2)$ & $8.3(4)$ & $3.3(2)$ & $4.6(3)$ & & & & & & & \\
\hline \multirow[t]{2}{*}{$\mathrm{NdGaO}_{3}$} & $177(2)$ & $234(2)$ & $134(2)$ & $189(2)$ & $8.3(1)$ & BM3 & $195(4)$ & $162(7)$ & $8.3(1)$ & BM2 & {$[30]$} \\
\hline & $6.7(6)$ & $7.7(3.9)$ & $5.7(6)$ & $7.5(7)$ & & & & & & & \\
\hline \multirow[t]{2}{*}{$\mathrm{NdCrO}_{3}$} & 191(2) & 251(3) & $147(2)$ & 203(3) & $20.6(1)$ & BM3 & $215(5)$ & $121(6)$ & $8.3(1)$ & BM2 & this work \\
\hline & $4.0(0.2)$ & $6.5(1.3)$ & $3.1(0.5)$ & $3.8(1.0)$ & & & & & & & \\
\hline
\end{tabular}

${ }^{a}$ Both unit-cell volume as well as unit-cell axes variation with pressure for $\mathrm{NdCrO}_{3}$ (this work) and $\mathrm{LaCrO}_{3}$ (from the structural refinements of Zhou et al., [31]) are fitted to a BM3-EoS, i.e., through the same EoS used to fit the pressure dependence for data of the orthogallate sample [30]. 




FIG. 3. The evolution of the normalized unit-cell volume (black hexagons) and polyhedral volumes (green squares and diamond for $\mathrm{NdO}_{12}$ and $\mathrm{CrO}_{6}$ polyhedra, respectively) with pressure for $\mathrm{NdCrO}_{3}$. Lines are the EoS fit to the data (see Table IV).

Table IV. Due to the high correlation between the volumetric bulk modulus $K_{T 0}$ and its pressure derivative $K_{0}^{\prime}$ (i.e., $K_{0}^{\prime}=$ $\left.\left(\partial K_{T 0} / \partial P\right)_{P=0}\right)$ [46], particularly at relatively low pressures, a realistic comparison of the volumetric changes of $\mathrm{La}$ and $\mathrm{Nd}$ perovskites is done by considering their $K_{T 0}$ obtained by a data fitting to a Birch-Murnaghan second-order equation of state (BM2-EoS), where $K_{0}^{\prime}=4$ [46]. As a matter of fact, both couples of perovskite oxides show very similar volumetric bulk moduli [i.e., 174(2) and 185(3) GPa for $\mathrm{LaGaO}_{3}$ and $\mathrm{LaCrO}_{3}$, and 187(1) and 191 (1) $\mathrm{GPa}$ for $\mathrm{NdGaO}_{3}$ and $\mathrm{NdCrO}_{3}$, respectively], corroborating the compressional schemes represented in Fig. 2. This implies that a mere difference based on the steric features of $\mathrm{Cr}^{3+}$ and $\mathrm{Ga}^{3+}$ hosted at the octahedral site does not clarify why $\mathrm{LaGaO}_{3}-\mathrm{LaCrO}_{3}$ and $\mathrm{NdGaO}_{3}-\mathrm{NdCrO}_{3}$ couples of perovskites undergo O-R phase transitions that are remarkably different in terms of temperature and pressure.

(a)

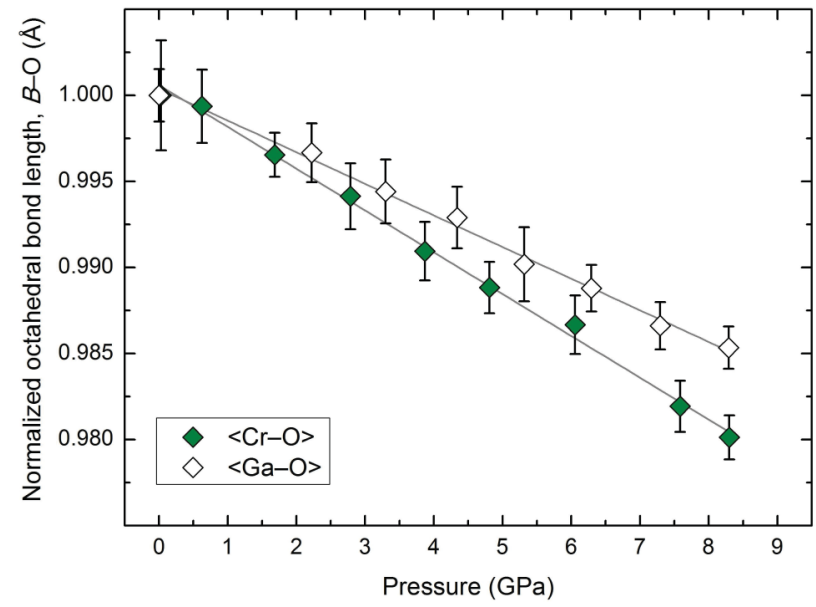

\section{B. Structural evolution}

In order to get further insights on the role of $\mathrm{Cr}^{3+}$ and $\mathrm{Ga}^{3+}$ ions hosted at the octahedral site, a detailed inspection of the structural evolution in the $\mathrm{NdGaO}_{3}-\mathrm{NdCrO}_{3}$ perovskite system is here reported.

Although $\mathrm{NdCrO}_{3}$ was previously investigated at both high-temperature and high-pressure conditions [32], several experimental difficulties limited the quality of data collected at high pressure, so hampering a reliable interpretation of the high-pressure evolution. Additionally, as highlighted by Angel et al. [30], the transition to the rhombohedral phase limits the pressure range over which the structural data can be collected for La compounds within the orthorhombic symmetry, precluding the stability of full refinement EoS parameters. For these reasons, a detailed review on the structural features with pressure of the $\mathrm{NdCrO}_{3}$ perovskite is proposed, and a comparison of the structural modifications for chromate and gallate perovskites will be confined to the $\mathrm{Nd}$ compounds.

Figure 3 shows that $\mathrm{NdCrO}_{3}$ has octahedra that are significantly more compressible than both the unit-cell volume and the $\mathrm{NdO}_{12}$ cubic site. An inspection of Table IV reveals that both $\mathrm{NdGaO}_{3}$ and $\mathrm{NdCrO}_{3}$ perovskites have similar compressional features. In particular, the polyhedral compressional scheme of both perovskites can be rationalized as: $K_{T 0} \approx K_{(A O 12) 0} \gg K_{(B O 6) 0}$. Nonetheless, $\mathrm{GaO}_{6}$ octahedra are significantly stiffer than $\mathrm{CrO}_{6}\left[\right.$ i.e, $K_{(\mathrm{GaO})}=162(7) \mathrm{GPa}$ and $K_{(\mathrm{CrO})}=121(6) \mathrm{GPa}$, respectively].

The more pronounced $\mathrm{CrO}_{6}$ octahedral compressibility can be ascribed to several concurrent factors:

(i) A significant compression (about $2 \%$ ) of the mean $\mathrm{Cr}-\mathrm{O}$ bond lengths is registered up to $8.3 \mathrm{GPa}$ (see Table III). As shown in Fig. 4(a), this bond shortening exceeds that of the $\mathrm{NdGaO}_{3}$ octahedra by about $0.5 \%$. For both $\mathrm{Nd}$ perovskites, the variation of the octahedral bond lengths is associated with a negligible change in the $\mathrm{O}-B-\mathrm{O}$ angles (Table III), which corresponds to a net volume reduction of the $\mathrm{BO}_{6}$ octahedra.

(ii) Both symmetry-independent $\mathrm{Cr}-\mathrm{O}-\mathrm{Cr}$ interoctahedral angles increase with pressure back towards $180^{\circ}$ [Fig. 4(b)], which corresponds to a decrease in the octahedral tilting.

(b)

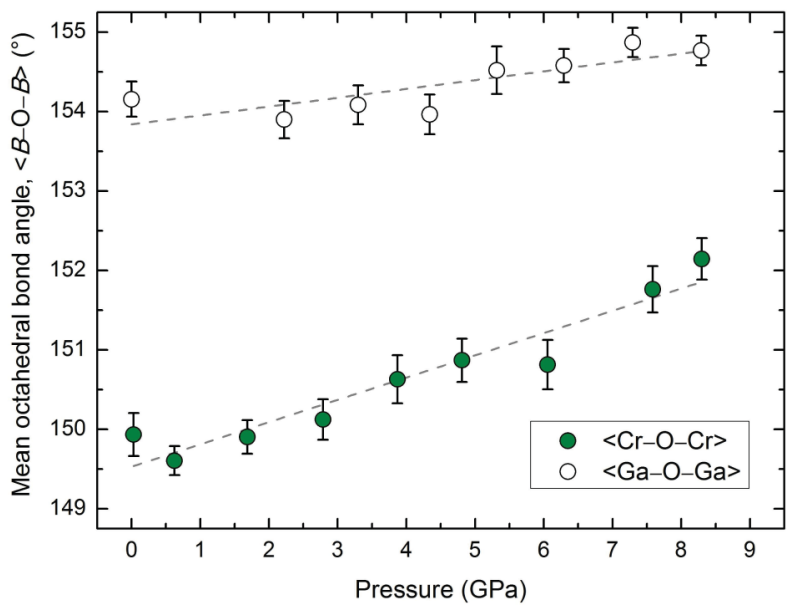

FIG. 4. Variation of average octahedral bond lengths (a) and bond angles (b) with pressure for $\mathrm{NdCrO}_{3}$ (filled symbols) and $\mathrm{NdGaO}$ [30] (empty symbols). Lines are the EoS fit to the data. Dashed lines are a reader's guide. 




FIG. 5. Pressure dependence of the effective coordination number $(\mathrm{ECoN})[47,48]$ at the octahedral site for $\mathrm{NdCrO}_{3}$ (filled symbols) and $\mathrm{NdGaO}_{3}$ [30] (empty symbols). Note: The effective cation coordination, as defined in ECoN, is estimated on the basis of a bondvalence like "bond weight" instead of using an arbitrary cutoff on the cation-ligand bond distances $[47,48]$. Hence, the ECoN variation provides information on the "bonding degree" and, as a consequence, on the polyhedral distortion with regard to the local environment in which cations are confined (in this case the perovskite octahedral site).

It is noteworthy that the mean interoctahedral variation for the $\mathrm{NdGaO}_{3}$ with respect to that of the $\mathrm{NdCrO}_{3}$ is about three times smaller in the same pressure range. It results that the enhanced compression of the $\mathrm{BO}_{6}$ octahedra in $\mathrm{NdCrO}_{3}$ is due to a greater shortening of the average octahedral bond lengths, accompanied by a faster rotation of the $\mathrm{CrO}_{6}$ octahedra, here represented by $\langle\mathrm{Cr}-\mathrm{O}-\mathrm{Cr}\rangle$ bond angles that increase more rapidly with pressure.

The structural features described above suggest that $\mathrm{GaO}_{6}$ octahedra behave as rigid units, while the $\mathrm{CrO}_{6}$ octahedra are more flexible and able to account for a higher degree

(a)

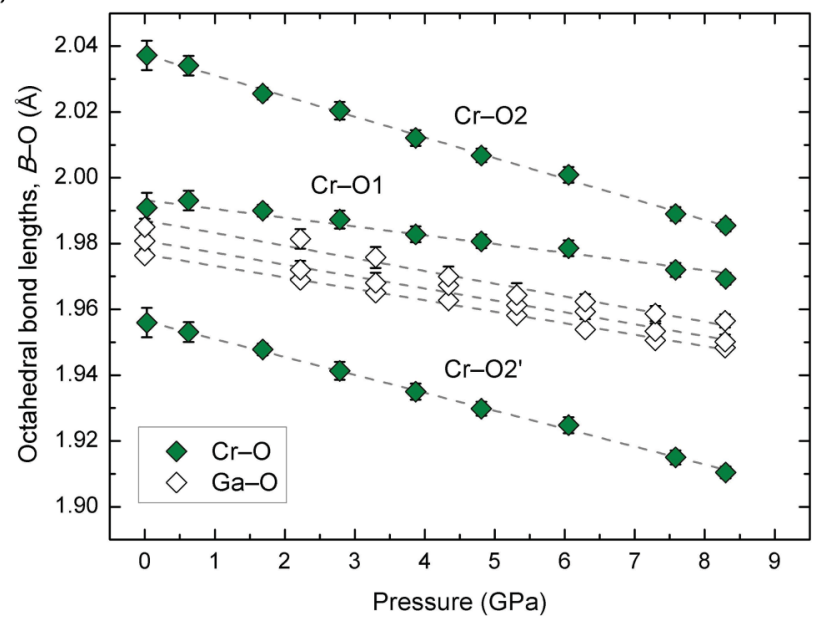

of compression and rotation, meaning that the compressional evolution of orthorhombic perovskites is closely connected to the nature of the constituting ions.

Further insights into the effects related to the nature of the $\mathrm{Cr}^{3+}$ and $\mathrm{Ga}^{3+}$ ions hosted at the octahedral site of the $\mathrm{Nd}$ perovskite structure can be derived by the effective coordination number $(\mathrm{ECoN})[47,48]$ variation with pressure.

The $\mathrm{GaO}_{6}$ octahedra have, within the uncertainties, a constant coordination number C.N. $\approx 6$ (i.e., the nominal coordination for an ideal octahedron) along the investigated pressure range. This means that $\mathrm{GaO}_{6}$ is a perfectly bonded polyhedron with a small degree of distortion, thus corroborating the concept of rigid unit (Fig. 5). As a matter of fact, at ambient conditions, $\mathrm{NdGaO}_{3}$ shows that the three pairs of octahedral bond lengths (as well as the two symmetryindependent interoctahedral bond angles) have similar values. As well represented in Fig. 6, this state is preserved on increasing pressure, i.e., $\mathrm{Ga}-\mathrm{O}$ bonds undergo a same degree of compression, and $\mathrm{Ga}-\mathrm{O}-\mathrm{Ga}$ angles are subjected to a similar increasing. This means that the $\mathrm{GaO}_{6}$ octahedra undergo an isotropic compression.

At variance with $\mathrm{NdGaO}_{3}$, the $\mathrm{ECoN}$ calculated for the octahedral site of the $\mathrm{NdCrO}_{3}$ perovskite is away from the octahedral ideal value. Without any significant change, the $\mathrm{ECoN}$ of $\mathrm{NdCrO}_{3}$ octahedra is 5.94 within the uncertainties (Fig. 5). At ambient conditions, the interoctahedral bond angles have similar values $\left(\approx 150^{\circ}\right)$, but the three pairs of $\mathrm{Cr}-\mathrm{O}$ bond lengths are quite different. The pressure dependence of the octahedral bond length [Fig. 6(a)] reveals that all the bond lengths are subjected to a regular decrease, but $\mathrm{Cr}-\mathrm{O} 1$ is remarkably stiffer than both $\mathrm{Cr}-\mathrm{O} 2$ and $\mathrm{Cr}-\mathrm{O} 2$ '. The observed anisotropy also entails the interoctahedral bond angles [Fig. 6(b)]. In fact, while $\mathrm{Cr}-\mathrm{O} 1-\mathrm{Cr}$ has a dependence on pressure similar to both the symmetry-independent $\mathrm{Ga}-\mathrm{O}-\mathrm{Ga}$ angles for $\mathrm{NdGaO}_{3}$ (the angular variation is $0.9^{\circ}$ and $0.7^{\circ}$ for $\mathrm{Cr}-\mathrm{O} 1-\mathrm{Cr}$ and $\mathrm{Ga}-\mathrm{O} 1,2-\mathrm{Ga}$, respectively), $\mathrm{Cr}-\mathrm{O} 2-\mathrm{Cr}$ increases more rapidly (by about $5^{\circ}$ ) up to $8.3 \mathrm{GPa}$.

Hence, the different electronic configuration of $\mathrm{Cr}^{3+}$ and $\mathrm{Ga}^{3+}$ hosted at the octahedral site allows the CFSE to act as a

(b)

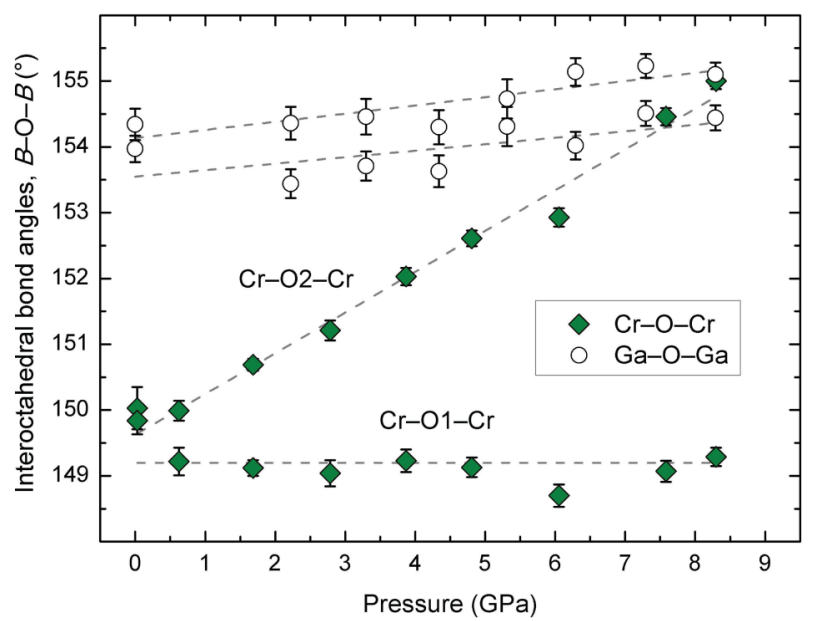

FIG. 6. Variation of octahedral bond lengths (a) and octahedral bond angles (b) with pressure for $\mathrm{NdCrO}_{3}$ (filled symbols) and $\mathrm{NdGaO}_{3}$ [30] (empty symbols). Dashed lines are a reader's guide. 
TABLE V. Electronic population for the $3 d$ orbitals of $\mathrm{Ga}^{3+}$ and $\mathrm{Cr}^{3+}$ ions hosted at octahedral sites of $\mathrm{NdGaO}_{3}$ and $\mathrm{NdCrO}_{3}$ perovskites at high pressure from Mulliken analysis calculation. Furthermore, actual electronic population along each cartesian axis (i.e., $x, y$, and $z$ in the same direction of $\mathrm{Cr}-\mathrm{O} 2^{\prime}, \mathrm{Cr}-\mathrm{O} 2$, and $\mathrm{Cr}-\mathrm{O} 1$ couples of octahedral bond lengths, respectively) at the $t_{2 g}$ level for the $\mathrm{NdCrO}_{3}$ perovskite.



vehicle of octahedral softening (in the case of octahedrally coordinated $\mathrm{Cr}^{3+}$ with partially filled $3 d$ orbitals) or it turns octahedra into rigid units when crystal field effects are absent (in the case of octahedrally coordinated $\mathrm{Ga}^{3+}$ with full $3 d$ orbitals).

\section{Mulliken population analysis}

The calculation of the electronic population for the $3 d$ orbitals of $\mathrm{Ga}^{3+}$ and $\mathrm{Cr}^{3+}$ ions hosted at octahedral sites of $\mathrm{Nd}$ perovskite compounds as a function of pressure is listed in Table V.

Such calculations unequivocally show that an electronic redistribution occurs at the $3 d$ orbitals of $\mathrm{Cr}^{3+}$ ions with pressure, while the electronic population of $\mathrm{Ga}^{3+}$ ions is not affected by the compressional regime (as both $e_{g}$ and $t_{2 g} 3 d$ orbitals are fully occupied). Albeit the summation of $\mathrm{Cr}^{3+} 3 d$ electrons is almost constant up to $\sim 13 \mathrm{GPa}$, and the electronic variation at the $e_{g}$ level is negligible (Table V), a tangible variation of the electronic population at the $t_{2 g}$ level is detected (Fig. 7), where $d_{x y}$ and $d_{x z}$ orbitals tend to compensate mutually.

\section{Experimental and computational coupling}

In order to compare the electronic distribution at the $t_{2 g}$ level of the $d$ orbitals with the long-range compressional features of the $\mathrm{NdCrO}_{3}$ perovskite (i.e., to obtain a match between XRD data and $a b$ intio calculations), the electronic population of the three $t_{2 g}$ orbitals has been recalculated along each cartesian axis, i.e., along the three couples of $\mathrm{Cr}-\mathrm{O}$ bond lengths (see Table V). Specifically, since $d_{x y}, d_{x z}$, and $d_{y z}$ orbitals have lobes projecting between the cartesian axes, chromium-oxygen bond distances at the octahedral site are their bisectors. Therefore, the electronic population along $x, y$, and $z$ cartesian axes (or $\mathrm{Cr}-\mathrm{O} 2^{\prime}, \mathrm{Cr}-\mathrm{O} 2$, and $\mathrm{Cr}-\mathrm{O} 1$ bond lengths, respectively) can be

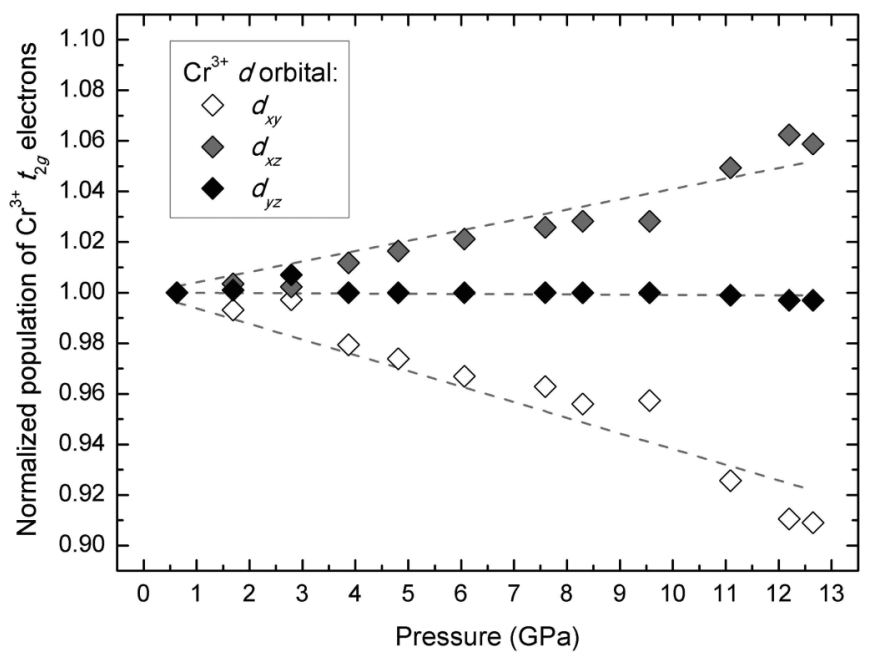

FIG. 7. Pressure dependence of the electronic population for $\mathrm{Cr}^{3+}$ $3 d$ orbitals in $\mathrm{NdCrO}_{3}$ perovskite at the $t_{2 g}$ level. Dashed lines are a reader's guide. 


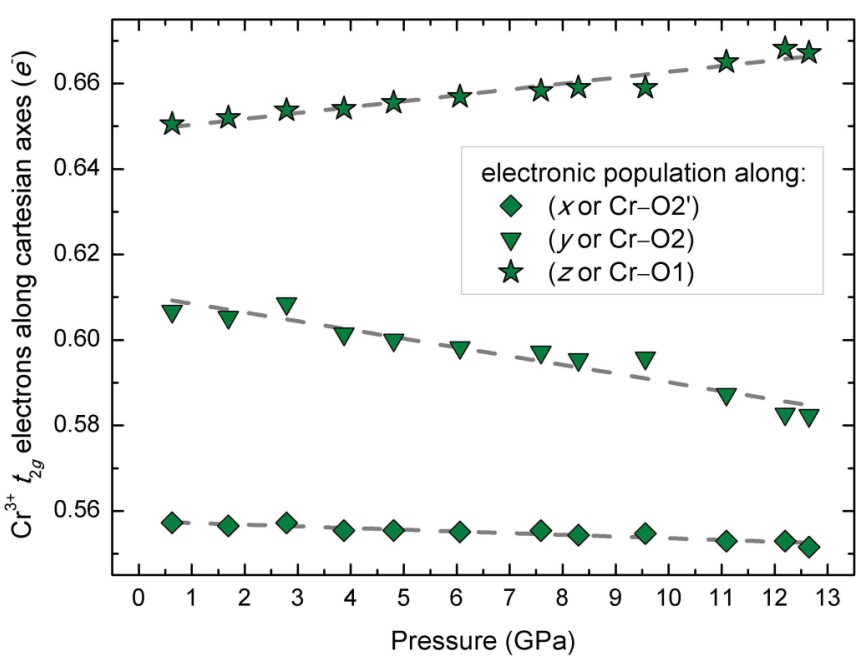

FIG. 8. Pressure dependence of the electronic population for $\mathrm{Cr}^{3+}$ $3 d$ orbitals in $\mathrm{NdCrO}_{3}$ perovskite at the $t_{2 g}$ level recalculated along $x, y$, and $z$ cartesian directions (or along the three pairs of $\mathrm{Cr}-\mathrm{O}$ bond lengths). Dashed lines are a reader's guide.

calculated by recasting, for each pressure point, the electronic population of $\mathrm{NdCrO}_{3}$ at the $t_{2 g}$ level through a system of linear equations that simultaneously account for the electronic content along each cartesian direction (or along the three pairs of symmetry independent $\mathrm{Cr}-\mathrm{O}$ bond lengths).

According to what was reported in the previous sections, Fig. 8 clearly shows that an electronic depletion along the $x$ and $y$ cartesian axes can be associated with a favored compression of both $\mathrm{Cr}-\mathrm{O} 2^{\prime}$ and $\mathrm{Cr}-\mathrm{O} 2$ bond lengths, while the electronic population increasing with pressure along the $z$ cartesian axis hinders the compression of the $\mathrm{Cr}-\mathrm{O} 1$ bond length [see also Fig. 6(a)].

Those data provide a clear indication on the CFSE effects at the $\mathrm{CrO}_{6}$ site for the $\mathrm{NdCrO}_{3}$ perovskite. In fact, the energetic splitting of the $3 d$ orbitals and, particularly the electronic redistribution at the $t_{2 g}$ level, explain why the metal-oxygen interactions are anisotropic.

\section{CONCLUDING REMARKS}

In situ high-pressure synchrotron XRD measurements coupled with $a b$ initio simulations of the electronic population from experimental structures of $\mathrm{NdCrO}_{3}$ orthorhombic perovskite have been compared with the compressional feature of an $\mathrm{NdGaO}_{3}$ isomorph [30]. Such a comparison let to appraise the role of the CFSE of ions hosted at the octahedral site.

The long-range compressional features (i.e., unit-cell parameters and volume) of $\mathrm{NdCrO}_{3}$ and $\mathrm{NdGaO}_{3}$ perovskite compounds are very similar, and therefore the steric contribution of $\mathrm{Cr}^{3+}$ and $\mathrm{Ga}^{3+}$ ions hosted at the octahedral site is the prevalent factor at this scale. Nevertheless, the different electronic configurations of these ions lead to a redistribution of electrons at the $3 d$ orbitals for $\mathrm{Cr}^{3+}$, which allows the CFSE to act as vehicle of octahedral softening in $\mathrm{NdCrO}_{3}$ or it turns octahedra into rigid units when CFSE is null, as in the case of $\mathrm{NdGaO}_{3}$.

These findings highlight the influence that a TMI can have on the compressional features of perovskite structures, and explain why both $\mathrm{La}^{3+} \mathrm{O}_{3}$ and $\mathrm{Nd}^{3+} \mathrm{O}_{3}$ (with $M=\mathrm{Cr}, \mathrm{Ga}$ ) members are characterized by largely different temperatures and pressures of transition. In addition, they have a deep repercussion on the way the compressibility of perovskite compounds has to be modeled. Subject of many reviews in which it has been rationalized as the combination of the relative compressibility of constituent $A \mathrm{O}_{12}$ and $B_{6} \mathrm{O}_{6}$ polyhedra with the octahedral tilts, the modeling of perovskite compounds on pressure has to rely also on the complexity derived from the intrinsic features of the constituent ions, i.e., the electronic configuration of octahedrally coordinated ions, as in the case of $\mathrm{Nd}^{3+} \mathrm{O}_{3}(M=\mathrm{Cr}$, $\mathrm{Ga})$ perovskites.

\section{ACKNOWLEDGMENTS}

The skillful assistance of the personnel at the ID27 HighPressure beamline (European Synchrotron Radiation Facility (ESRF), Grenoble, France), and in particular the assistance and technical suggestions of Dr. Volodymyr Svitlyk, are gratefully acknowledged. ESRF is further acknowledged for provision of beamtime to Proposal No. CH-4541.
[1] X. Renshaw Wang, C. J. Li, W. M. Lü, T. R. Paudel, D. P. Leusink, M. Hoek, N. Poccia, A. Vailionis, T. Venkatesan, J. M. D. Coey, E. Y. Tsymbal, Ariando, and H. Hilgenkamp, Science 349, 716 (2015).

[2] G. Grancini, C. Roldán-Carmona, I. Zimmermann, E. Mosconi, X. Lee, D. Martineau, S. Narbey, F. Oswald, F. De Angelis, M. Graetzel, and M. K. Nazeeruddin, Nat. Commun. 8, 15684 (2017)

[3] S. S. Shin, E. J. Yeom, W. S. Yang, S. Hur, M. G. Kim, J. Im, J. Seo, J. H. Noh, and S. I. Seok, Science 356, 167 (2017).

[4] T. Duffy, Nature (London) 506, 427 (2014).

[5] N. Tsujino, Y. Nishihara, D. Yamazaki, Y. Seto, Y. Higo, and E. Takahashi, Nature (London) 539, 81 (2016).

[6] A. Kurnosov, H. Marquardt, D. J. Frost, T. Boffa Ballaran, and L. Ziberna, Nature (London) 543, 543 (2017).
[7] R. H. Mitchell, Perovskites: Modern and Ancient (Almaz Press, Thunder Bay, Ontario, Canada, 2002).

[8] A. M. Glazer, Acta Crystallogr. Sect. B 28, 3384 (1972).

[9] P. M. Woodward, Acta Crystallogr. Sect. B 53, 32 (1997).

[10] M. Avdeev, E. N. Caspi, and S. Yakovlev, Acta Crystallogr. Sect. B 63, 363 (2007).

[11] D. Andrault and J. P. Poirier, Phys. Chem. Miner. 18, 91 (1991).

[12] N. W. Thomas, Acta Crystallogr. Sect. B 54, 585 (1998).

[13] J. Zhao, N. L. Ross, and R. J. Angel, Acta Crystallogr. Sect. B 60, 263 (2004).

[14] T. Yagi, H.-K. Mao, and P. M. Bell, Phys. Chem. Miner. 3, 97 (1978).

[15] M. O'Keeffe, B. G. Hyde, and J.-O. Bovin, Phys. Chem. Miner. 4, 299 (1979). 
[16] R. J. Angel, J. Zhao, and N. L. Ross, Phys. Rev. Lett. 95, 025503 (2005).

[17] M. Ardit, M. Dondi, and G. Cruciani, in Lattice Distortion Upon Compression in Orthorhombic Perovskite: Review and Development of a Predictive Tool, edited by S. V. Krivovichev, Minerals as Advanced Materials II (Springer, Berlin, 2011).

[18] M. Ardit, G. Cruciani, M. Dondi, M. Merlini, and P. Bouvier, Phys. Rev. B 82, 064109 (2010).

[19] M. Ardit, J. Phys. Chem. Solids 87, 203 (2015).

[20] M. Ardit, M. Dondi, and G. Cruciani, Phys. Rev. B 95, 024110 (2017).

[21] S. Sasaki, C. T. Prewitt, and R. C. Liebermann, Am. Mineral. 68, 1189 (1983).

[22] N. A. Benedek, A. T. Mulder, and C. J. Fennie, J. Solid State Chem. 195, 11 (2012).

[23] L. Bindi, E. A. Sirotkina, A. V. Bobrov, and T. Irifune, Am. Mineral. 99, 866 (2014).

[24] L. Bindi, E. A. Sirotkina, A. V. Bobrov, M. J. Walter, D. Pushcharovsky, and T. Irifune, Am. Mineral. 102, 227 (2017).

[25] A. Senyshyn, L. Vasylechko, M. Knappb, U. Bismayer, M. Berkowski, and A. Matkovskii, J. Alloy. Compd. 382, 84 (2004).

[26] T. Hashimoto, N. Matsushita, Y. Murakami, N. Kojima, K. Yoshida, H. Tagawa, M. Dokiya and T. Kikegawa, Solid State Commun. 108, 691 (1998).

[27] B. J. Kennedy, T. Vogt, C. D. Martin, J. B. Parise, and J. A. Hriljac, J. Phys.: Condens. Matter 13, L925 (2001).

[28] A. Senyshyn, J. M. Engel, I. D. H. Oswald, L Vasylechko, and M. Berkowski, Z. Kristallogr. Suppl. 30, 341 (2009).

[29] T. Shibasaki, T. Furuya, J. Kuwahara, Y. Takahashi, H. Takahashi, and T. Hashimoto, J. Therm. Anal. Calorim. 81, 575 (2005).

[30] R. J. Angel, J. Zhao, N. L. Ross, C. V. Jakeways, S. A. T. Redfern, and M. Berkowski, J. Solid State Chem. 180, 3408 (2007).

[31] J.-S. Zhou, J. A. Alonso, A. Muoñz, M. T. Fernández-Díaz, and J. B. Goodenough, Phys. Rev. Lett. 106, 057201 (2011).
[32] M. W. Lufaso, S. J. Mugavero, III, W. R. Gemmill, Y. Lee, T. Vogt, and H.-C. zur Loye, J. Alloy. Compd. 433, 91 (2007).

[33] R. G. Burns, Mineralogical Application of Crystal Field Theory, 2nd ed. (Cambridge University Press, Cambridge, 1993).

[34] M. Mezouar, W. A. Crichton, S. Bauchau, F. Thurel, H. Witsch, F. Torrecillas, G. Blattmann, P. Marion, Y. Dabin, J. Chavanne, O. Hignette, C. Morawe, and C. Borel, J. Synchrotron Radiat. 12, 659 (2005).

[35] H. K. Mao, J. Xu, and P. M. Bell, J. Geophys. Res. Solid Earth 91, 4673 (1986).

[36] C. Prescher and V. B. Prakapenka, High Pressure Res. 35, 223 (2015).

[37] A. C. Larson and R. B. Von Dreele, General Structure Analysis System (GSAS), Los Alamos National Laboratory Report No. LAUR 86 748, Los Alamos National Laboratory, New Mexico, USA, 1988.

[38] H. Toby, J. Appl. Crystallogr. 34, 210 (2001).

[39] R. Dovesi, V. R. Saunders, C. Roetti, R. Orlando, C. M. ZicovichWilson, F. Pascale, B. Civalleri, K. Doll, N. M. Harrison, I. J. Bush, Ph. D'Arco, M. Llunel, M. Causà, and Y. Noël, CRYSTAL14 User's manual (University of Torino, Turin, Italy, 2014).

[40] Z. Wu and R. E. Cohen, Phys. Rev. B 73, 235116 (2006).

[41] F. Corà, Mol. Phys. 103, 2483 (2005).

[42] M. Catti, G. Sandrone, G. Valerio, and R. Dovesi, J. Phys. Chem. Solids 57, 1735 (1996).

[43] R. Pandey, J. E. Jaffe, and N. M. Harrison, J. Phys. Chem. Solids 55, 1357 (1994).

[44] M. Towler, CRYSTAL Resources Page, Theory of Condensed Matter http://www.tcm.phy.cam.ac.uk/ mdt26/crystal.html (2015).

[45] H. J. Monkhorst and J. D. Pack, Phys. Rev. B 13, 5188 (1976).

[46] R. J. Angel, Rev. Mineral. Geochem. 41, 35 (2000).

[47] R. Hoppe, Z. Kristallogr. 150, 23 (1979).

[48] R. Hoppe, S. Voigt, H. Glaum, J. Kissel, H. P. Müller, and K. Bernet, J. Less-Common Met. 156, 105 (1989). 